\title{
Complete genome sequence of Desulfobulbus propionicus type strain $\left(1 \mathrm{pr} 3^{\mathrm{T}}\right)$
}

\author{
Ioanna Pagani ${ }^{1}$, Alla Lapidus ${ }^{1}$, Matt Nolan${ }^{1}$, Susan Lucas ${ }^{1}$, Nancy Hammon ${ }^{1}$, Shweta Desh- \\ pande $^{1}$, Jan-Fang Cheng1 , Olga Chertkov ${ }^{1,2}$, Karen Davenport ${ }^{1,2}$, Roxane Tapia ${ }^{1,2}$, Cliff Han ${ }^{1,2}$, \\ Lynne Goodwin ${ }^{1,2}$, Sam Pitluck ${ }^{1}$, Konstantinos Liolios ${ }^{1}$, Konstantinos Mavromatis ${ }^{1}$, Natalia \\ Ivanova ${ }^{1}$, Natalia Mikhailova', Amrita Pati ${ }^{1}$, Amy Chen ${ }^{3}$, Krishna Palaniappan ${ }^{3}$, Miriam \\ Land $^{1,4}$, Loren Hauser ${ }^{1,4}$, Yun-Juan Chang ${ }^{1,4}$, Cynthia D. Jeffries ${ }^{1,4}$, John C. Detter ${ }^{1,2}$, Evelyne \\ Brambilla $^{5}$, K. Palani Kannan ${ }^{5}$, Olivier D. Ngatchou Djao ${ }^{6}$, Manfred Rohde $^{6}$, Rüdiger Pukall ${ }^{5}$, \\ Stefan Spring ${ }^{5}$, Markus Göker ${ }^{5}$, Johannes Sikorski ${ }^{5}$, Tanja Woyke ${ }^{1}$, James Bristow ${ }^{1}$, Jonathan \\ A. Eisen ${ }^{1,7}$, Victor Markowitz ${ }^{3}$, Philip Hugenholtz ${ }^{1,8}$, Nikos C. Kyrpides ${ }^{1}$, and Hans-Peter \\ Klenk $^{5 *}$ \\ ${ }^{1}$ DOE Joint Genome Institute, Walnut Creek, California, USA \\ ${ }^{2}$ Los Alamos National Laboratory, Bioscience Division, Los Alamos, New Mexico, USA \\ ${ }^{3}$ Biological Data Management and Technology Center, Lawrence Berkeley National \\ Laboratory, Berkeley, California, USA \\ ${ }^{4}$ Oak Ridge National Laboratory, Oak Ridge, Tennessee, USA \\ ${ }^{5}$ DSMZ - German Collection of Microorganisms and Cell Cultures GmbH, Braunschweig, \\ Germany \\ ${ }^{6}$ HZI - Helmholtz Centre for Infection Research, Braunschweig, Germany \\ ${ }^{7}$ University of California Davis Genome Center, Davis, California, USA \\ ${ }^{8}$ Australian Centre for Ecogenomics, School of Chemistry and Molecular Biosciences \\ The University of Queensland, Brisbane, Australia \\ *Corresponding author: Hans-Peter Klenk
}

Keywords: anaerobic, non-motile, Gram-negative, chemoorganotroph, ellipsoidal to lemonshaped, non spore-forming, mesophilic, Desulfobulbaceae, GEBA

Desulfobulbus propionicus Widdel 1981 is the type species of the genus Desulfobulbus, which belongs to the family Desulfobulbaceae. The species is of interest because of its great implication in the sulfur cycle in aquatic sediments, its large substrate spectrum and a broad versatility in using various fermentation pathways. The species was the first example of a pure culture known to disproportionate elemental sulfur to sulfate and sulfide. This is the first completed genome sequence of a member of the genus Desulfobulbus and the third published genome sequence from a member of the family Desulfobulbaceae. The 3,851,869 bp long genome with its 3,351 protein-coding and 57 RNA genes is a part of the Genomic Encyclopedia of Bacteria and Archaea project.

\section{Introduction}

Strain 1pr3 ${ }^{\mathrm{T}}$ "Lindhorst" (= DSM 2032 = ATCC $33891=$ VKM B-1956) is the type strain of the species Desulfobulbus propionicus, which is the type species of the genus Desulfobulbus $[1,2]$. The genus currently consists of five validly published named species [3]. The genus name is derived from the Neo-Latin word 'desulfo-' meaning 'desulfurizing' and the Latin word 'bulbus' meaning 'a bulb or an onion', yielding the 'onion-shaped sulfate reducer' [2]. The species epithet is derived from the Neo-Latin word 'acidum propionicum' and the Latin suffix '-icus' in the sense of 'pertaining to'; 'propionicus' = 'pertaining to propionic acid' [2]. Strain 1pr3 "Lindhorst" was isolated by Fritz Widdel in 1982 from anaerobic mud of a village ditch in Lindhorst near Hannover [4]. Other strains have been isolated from anaerobic mud in a forest pond near Hannover and from a 
mud flat of the Jadebusen (North Sea) [4], from an anaerobic intertidal sediment in the Ems-Dollard estuary (Netherlands) [5], and from a sulfatereducing fluidized bed reactor inoculated with mine sediments and granular sludge [6]. Several studies have been carried out on the metabolic pathways of the strain 1 pr3 $3^{\mathrm{T}}[4,7,8]$. Here we present a summary classification and a set of features for D. propionicus strain $1 \mathrm{pr} 3^{\mathrm{T}}$, together with the description of the complete genomic sequencing and annotation.

\section{Classification and features}

A representative genomic $16 \mathrm{~S}$ rRNA sequence of strain 1 pr $3^{\mathrm{T}}$ was compared using NCBI BLAST under default settings (e.g., considering only the highscoring segment pairs (HSPs) from the best 250 hits) with the most recent release of the Greengenes database [9] and the relative frequencies, weighted by BLAST scores, of taxa and keywords (reduced to their stem [10]) were determined. The four most frequent genera were Desulfobulbus (76.1\%), Desulfurivibrio (11.9\%), Desulforhopalus (8.1\%) and Desulfobacterium (3.9\%) (19 hits in total). Regarding the eleven hits to sequences from members of the species, the average identity within HSPs was $95.1 \%$, whereas the average coverage by HSPs was $94.7 \%$. Regarding the nine hits to se- quences from other members of the genus, the average identity within HSPs was $94.9 \%$, whereas the average coverage by HSPs was $94.9 \%$. Among all other species, the one yielding the highest score was Desulfobulbus elongatus, which corresponded to an identity of $96.9 \%$ and an HSP coverage of 93.8\%. The highest-scoring environmental sequence was FJ517134 ("semiarid 'Tablas de Daimiel National Park' wetland (Central Spain) unraveled water clone TDNP Wbc97 921 234'), which showed an identity of $97.8 \%$ and a HSP coverage of $98.3 \%$. The five most frequent keywords within the labels of environmental samples which yielded hits were 'sediment' (8.4\%), 'marin' (2.9\%), 'microbi' (2.5\%), 'sea' (1.7\%) and 'seep' (1.7\%) (231 hits in total). These keywords are in line with habitats from which the cultivated strains of $D$. propionicus were isolated. Environmental samples which resulted in hits of a higher score than the highest scoring species were not found.

Figure 1 shows the phylogenetic neighborhood of D. propionicus in a $16 \mathrm{~S}$ rRNA based tree. The sequences of the two 16S rRNA gene copies in the genome do not differ from each other, and differ by two nucleotides from the previously published 16S rRNA sequence (AY548789).

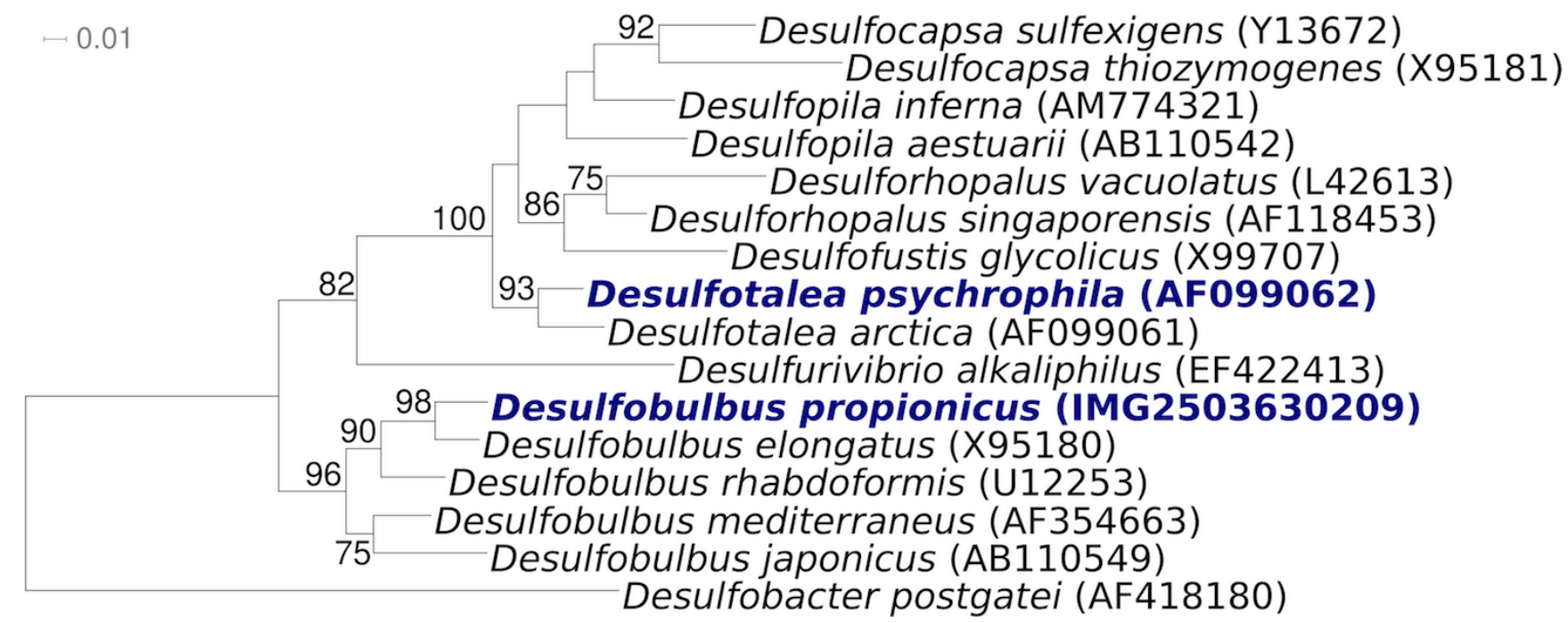

Figure 1. Phylogenetic tree highlighting the position of D. propionicus relative to the other type strains within the family Desulfobulbaceae. The tree was inferred from 1,425 aligned characters [11,12] of the 16S rRNA gene sequence under the maximum likelihood criterion [13] and rooted in accordance with the current taxonomy. The branches are scaled in terms of the expected number of substitutions per site. Numbers above branches are support values from 200 bootstrap replicates [14] if larger than 60\%. Lineages with type strain genome sequencing projects registered in GOLD [15] are shown in blue, published genomes [16] in bold. 
The cells of $D$. propionicus are ellipsoidal to lemonshaped (1-1.3 by 1.8-2 $\mu \mathrm{m}$ ) (Figure 2). D. propionicus is a Gram-negative and non-sporulating bacterium (Table 1) that produces fimbriae [4]. The temperature range for growth is between $10^{\circ} \mathrm{C}$ and $43^{\circ} \mathrm{C}$, with an optimum at $39^{\circ} \mathrm{C}$ [4]. The $\mathrm{pH}$ range for growth is between 6.0 and 8.6, with an optimum at $\mathrm{pH}$ 7.1-7.5 [4]. Strain $1 \mathrm{pr}^{\mathrm{T}}$ is described to be nonmotile, with no flagellum detected by electron microscopy [4], although the genome sequence suggests it to be comprehensively equipped with the genes required for flagellar assembly (see below). The closely related strains 2 pr4 and 3pr10 were motile by a single polar flagellum [4], suggesting either a recent mutational loss of flagellar motility in strain $1 \mathrm{pr} 3^{\mathrm{T}}$, or a failure to express the genes under the conditions of growth. D. propionicus was initially described to be a strictly anaerobic chemoorganotroph [4]. Further studies a decade later indicated that this organism was able to grow in the presence of oxygen while oxidizing sulfide, elemental sulfur, sulfite and polysulfide to sulfate [27], where mainly thiosulfate was formed from elemental sulfur $[27,28]$. D. propionicus is the first example of a pure culture known to disproportionate elemental sulfur to sulfate and sulfide [7]. But growth of $D$. propionicus with elemental sulfur as the electron donor and Fe(III) as a sulfide sink and/or electron acceptor was very slow [7]. It ferments three moles of pyruvate to two moles acetate and one mole of propionate stoichiometrically via the methylmalonyl-CoA pathway [8]. Strain $1 \mathrm{pr} 3^{\mathrm{T}}$ was also found to reduce iron to sustain growth [7]. Fe(III) greatly stimulated sulfate production, and D. propionicus produced as much sulfate in the absence of Mn(IV) or Fe(III) as it did with Mn(IV) [7]. In the absence of sulfate, ethanol is fermented to propionate and acetate in a molar ratio of $2: 1$ [24], while $i$-propanol is produced during the fermentation of ethanol [24]. In the presence of $\mathrm{H}_{2}$ and $\mathrm{CO}_{2}$, ethanol is quantitatively converted to propionate [24]. $\mathrm{H}_{2}$-plus sulfate-grown cells of the strain $1 \mathrm{pr} 3^{\mathrm{T}}$ were able to oxidize 1 -propanol and 1-butanol to propionate and butyrate respectively with the concomitant reduction of acetate plus $\mathrm{CO}_{2}$ to propionate [24]. Growth on $\mathrm{H}_{2}$ required acetate as a carbon source in the presence of $\mathrm{CO}_{2}$ [4]. Strain $1 \mathrm{pr}^{\mathrm{T}}$ is also able to grow mixotrophi- cally on $\mathrm{H}_{2}$ in the presence of an organic compound [24]. When the amounts of sulfate and ethanol are limiting, D. propionicus competes successfully with Desulfobacter postgatei, another sulfate reducer [29]. Propionate, lactate, ethanol and propanol were used as electron donors and carbon sources [4]. Together with pyruvate, they are oxidized to acetate as an end-product [4]. Butyrate may be used in a few cases [4]. Sulfide oxidation in D. propionicus is biphasic, proceeding via oxidation to elemental sulfur, followed by sulfur disproportionation to sulfide and sulfate $[7,27,30]$. However, the uncoupler tetrachlorosalicylanilide (TCS) and the electron transport inhibitor myxothiazol inhibited sulfide oxidation to sulfate and caused accumulation of sulfur [30]. But in the presence of the electron transport inhibitor 2- $n$ heptyl-4-hydroxyquinoline- $N$-oxide (HQNO), sulfite and thiosulfate were formed [30]. When grown on lactate or pyruvate, the strain $1 \mathrm{pr} 3^{\mathrm{T}}$ is able to grow without an external electron acceptor and formed propionate and acetate as fermentation products $[4,31]$. For this purpose, the substrates are fermented via the methylmalonyl-CoA pathway [31]. In the cells of $D$. propionicus, the activities of methylmalonyl-CoA: pyruvate transcarboxylase, a key enzyme of methylmalonyl-CoA pathway, as well as the other enzymes (pyruvate dehydrogenase, succinate dehydrogenase and malate dehydrogenase) involved in the pathway were detected [31]. D. propionicus can convert not only pyruvate but also alcohols via methylmalonyl-CoA pathway in the absence of sulfate $[24,32,33]$. Inorganic pyrophosphatase was present in strain $1 \mathrm{pr} 3^{\mathrm{T}}$ at high levels of activity, but the enzyme was $\mathrm{Mg}^{2+}$-dependent and stimulated by $\mathrm{Na}_{2} \mathrm{~S}_{2} \mathrm{O}_{4}$ [34]. However, isocitrate lyase and pyrophosphate-dependent acetate kinase were not detected [34]. Sulfate, sulfite and thiosulfate serve as electron acceptors and are reduced to $\mathrm{H}_{2} \mathrm{~S}$, but not elemental sulfur, malate, fumarate [4]. Nitrate also served as electron acceptor and was reduced to ammonia [4,27]. Acetate, valerate, higher fatty acids, succinate, fumarate, malate, sugars are not utilized [4]. Strain $1 \mathrm{pr} 3^{\mathrm{T}}$ requires 4 -aminobenzoic acid as growth factor $[4,6]$. Cell membrane and cytoplasmic fraction contain b- and c-type cytochromes [4]. 




Figure 2. Scanning electron micrograph of D. propionicus $1 \mathrm{pr} 3^{\top}$

\section{Chemotaxonomy}

Odd-chain fatty acids predominated in the fatty acid profile of the strain $1 \mathrm{pr} 3^{\mathrm{T}}(77 \%$ of the total fatty acids $v$ s. $23 \%$ for the even-chain fatty acids) $[35,36]$, reflecting the use of propionate as a chain initiator for fatty acid biosynthesis [35]. The major fatty acids, when grown on propionate, were found to be $\mathrm{C}_{17: 1 \omega 6}(51.5 \%), \mathrm{C}_{15: 0}(28.3 \%), \mathrm{C}_{16: 0}$ (6.9\%), $\mathrm{C}_{14: 0}(5.2 \%), \mathrm{C}_{18: 0}(3.1 \%), \mathrm{C}_{15: 1} \omega 6$ and $\mathrm{C}_{16: 1}$ $\omega 5,\left(2.4 \%\right.$ each) and $\mathrm{C}_{18: 1 \omega 7}(2.1 \%)$. The minor fatty acids were $\mathrm{C}_{17: 0}\left(0.6 \%\right.$ of the total fatty acids), $\mathrm{C}_{16: 1}$ $\omega 7(0.9 \%), \mathrm{C}_{18: 1 \omega 9}$ and $\mathrm{C}_{15: 1 \Delta 7}\left(1.0 \%\right.$ each), $\mathrm{C}_{12: 0}$ (1.3\%), $\mathrm{C}_{17: 1 \omega 8}(1.6 \%)$ and $\mathrm{C}_{13: 0}(1.7 \%)$ [36].

\section{Genome sequencing and annotation Genome project history}

This organism was selected for sequencing on the basis of its phylogenetic position [37], and is part of the Genomic Encyclopedia of Bacteria and Arc- haea project [38]. The genome project is deposited in the Genomes OnLine Database [15] and the complete genome sequence is deposited in GenBank. Sequencing, finishing and annotation were performed by the DOE Joint Genome Institute (JGI). A summary of the project information is shown in Table 2.

\section{Growth conditions and DNA isolation}

D. propionicus 1pr3T ${ }^{\mathrm{T}}$ DSM 2032, was grown anaerobically in DSMZ medium 194 (Desulfobulbus medium) [39] at $37^{\circ} \mathrm{C}$. DNA was isolated from 0.5$1 \mathrm{~g}$ of cell paste using MasterPure Gram-positive DNA purification kit (Epicentre MGP04100) following the standard protocol as recommended by the manufacturer, with modification st/LALM for cell lysis as described in Wu et al. [38]. DNA is available through the DNA Bank Network $[40,41]$. 
Table 1. Classification and general features of D. propionicus $1 \mathrm{pr} 3^{\top}$ according to the MIGS recommendations [17].

\begin{tabular}{|c|c|c|c|}
\hline MIGS ID & Property & Term & Evidence code \\
\hline & \multirow{8}{*}{ Current classification } & Domain Bacteria & TAS [18] \\
\hline & & Phylum Proteobacteria & TAS [19] \\
\hline & & Class Deltaproteobacteria & TAS $[20,21]$ \\
\hline & & Order Desulfobacterales & TAS $[20,22]$ \\
\hline & & Family Desulfobulbaceae & TAS $[20,23]$ \\
\hline & & Genus Desulfobulbus & TAS $[1,2]$ \\
\hline & & Species Desulfobulbus propionicus & TAS $[1,2]$ \\
\hline & & Type strain $1 \mathrm{pr} 3$ & TAS [4] \\
\hline & Gram stain & negative & TAS [4] \\
\hline & Cell shape & ellipsoidal to lemon-shaped & TAS [4] \\
\hline & Motility & non-motile & TAS [4] \\
\hline & Sporulation & none & TAS [4] \\
\hline & Temperature range & $10^{\circ} \mathrm{C}-43^{\circ} \mathrm{C}$ & TAS [4] \\
\hline & Optimum temperature & $39^{\circ} \mathrm{C}$ & TAS [4] \\
\hline & Salinity & not reported & NAS \\
\hline \multirow[t]{3}{*}{ MIGS-22 } & Oxygen requirement & anaerobic & TAS [4] \\
\hline & Carbon source & propionate, lactate, ethanol, propanol, pyruvate & TAS $[4,6]$ \\
\hline & Energy source & chemoorganotroph & TAS [4] \\
\hline MIGS-6 & Habitat & anaerobic freshwater sediments & TAS $[24]$ \\
\hline MIGS-15 & Biotic relationship & not reported & NAS \\
\hline \multirow[t]{3}{*}{ MIGS-14 } & Pathogenicity & not reported & NAS \\
\hline & Biosafety level & 1 & TAS [25] \\
\hline & Isolation & anaerobic mud & TAS [4] \\
\hline MIGS-4 & Geographic location & Lindhort near Hannover, Germany & TAS [4] \\
\hline MIGS-5 & Sample collection time & 1980 or before & NAS \\
\hline MIGS-4.1 & Latitude & 52.38 & NAS \\
\hline MIGS-4.2 & Longitude & 9.82 & NAS \\
\hline MIGS-4.3 & Depth & not reported & NAS \\
\hline MIGS-4.4 & Altitude & not reported & NAS \\
\hline
\end{tabular}

Evidence codes - IDA: Inferred from Direct Assay (first time in publication); TAS: Traceable Author Statement (i.e., a direct report exists in the literature); NAS: Non-traceable Author Statement (i.e., not directly observed for the living, isolated sample, but based on a generally accepted property for the species, or anecdotal evidence). These evidence codes are from of the Gene Ontology project [26]. If the evidence code is IDA, then the property was directly observed by one of the authors or an expert mentioned in the acknowledgements. 
Table 2. Genome sequencing project information

\begin{tabular}{lll}
\hline MIGS ID & Property & Term \\
\hline MIGS-31 & Finishing quality & Finished \\
MIGS-28 & Libraries used & Three genomic libraries:one 454 pyrosequence standard library, one 454 PE \\
& library (12 kb insert size), one Illumina library \\
MIGS-29 & Sequencing platforms & Illumina GAii, 454 GS FLX Titanium \\
MIGS-31.2 & Sequencing coverage & $109.7 \times$ Illumina; 37.9 × pyrosequence \\
MIGS-30 & Assemblers & Newbler version 2.0.00.20- PostRelease-11-05-2008-gcc-3.4.6, Velvet, phrap \\
MIGS-32 & Gene calling method & Prodigal 1.4, GenePRIMP \\
& INSDC ID & CP002364 \\
& Genbank Date of Release & January 28, 2011 \\
& GOLD ID & Gc01599 \\
& NCBI project ID & 32577 \\
& Database: IMG-GEBA & 2503538026 \\
& Source material identifier & DSM 2032 \\
& Project relevance & Tree of Life, GEBA \\
\hline
\end{tabular}

\section{Genome sequencing and assembly}

The genome was sequenced using a combination of Illumina and 454 sequencing platforms. All general aspects of library construction and sequencing can be found at the JGI website [42]. Pyrosequencing reads were assembled using the Newbler assembler version 2.0.00.20-PostRelease-11-05-2008-gcc3.4.6 (Roche). The initial Newbler assembly consisting of 35 contigs in two scaffolds was converted into a phrap [43] assembly by making fake reads from the consensus, to collect the read pairs in the 454 paired end library. Illumina GAii sequencing data $(327 \mathrm{Mb})$ was assembled with Velvet [44] and the consensus sequences were shredded into $1.5 \mathrm{~kb}$ overlapped fake reads and assembled together with the 454 data. The 454 draft assembly was based on $145.0 \mathrm{Mb} 454$ draft data and all of the 454 paired end data. Newbler parameters are -consed a 50 -l 350 -g -m -ml 20. The Phred/Phrap/Consed software package [43] was used for sequence assembly and quality assessment in the subsequent finishing process. After the shotgun stage, reads were assembled with parallel phrap (High Performance Software, LLC). Possible mis-assemblies were corrected with gapResolution [42], Dupfinisher [45], or sequencing cloned bridging PCR fragments with subcloning or transposon bombing (Epicentre Biotechnologies, Madison, WI). Gaps between contigs were closed by editing in Consed, by PCR and by Bubble PCR primer walks (J.F.Chang, unpublished). A total of 563 additional reactions and five shatter libraries were necessary to close gaps and to raise the quality of the finished sequence. Illumina reads were also used to correct potential base errors and increase consensus quali- ty using a software Polisher developed at JGI [46]. The error rate of the completed genome sequence is less than 1 in 100,000. Together, the combination of the Illumina and 454 sequencing platforms provided $147.6 \times$ coverage of the genome. The final assembly contained 475,513 pyrosequence and $11,740,513$ Illumina reads.

\section{Genome annotation}

Genes were identified using Prodigal [47] as part of the Oak Ridge National Laboratory genome annotation pipeline, followed by a round of manual curation using the JGI GenePRIMP pipeline [48]. The predicted CDSs were translated and used to search the National Center for Biotechnology Information (NCBI) nonredundant database, UniProt, TIGR-Fam, Pfam, PRIAM, KEGG, COG, and InterPro databases. Additional gene prediction analysis and functional annotation was performed within the Integrated Microbial Genomes - Expert Review (IMG-ER) platform [49].

\section{Genome properties}

The genome consists of a 3,851,869 bp long chromosome with a GC content of $58.9 \%$ (Table 3 and Figure 3). Of the 3,408 genes predicted, 3,351 were protein-coding genes, and 57 RNAs; 68 pseudogenes were also identified. The majority of the proteincoding genes $(70.5 \%)$ were assigned with a putative function while the remaining ones were annotated as hypothetical proteins. The distribution of genes into COGs functional categories is presented in Table 4. 


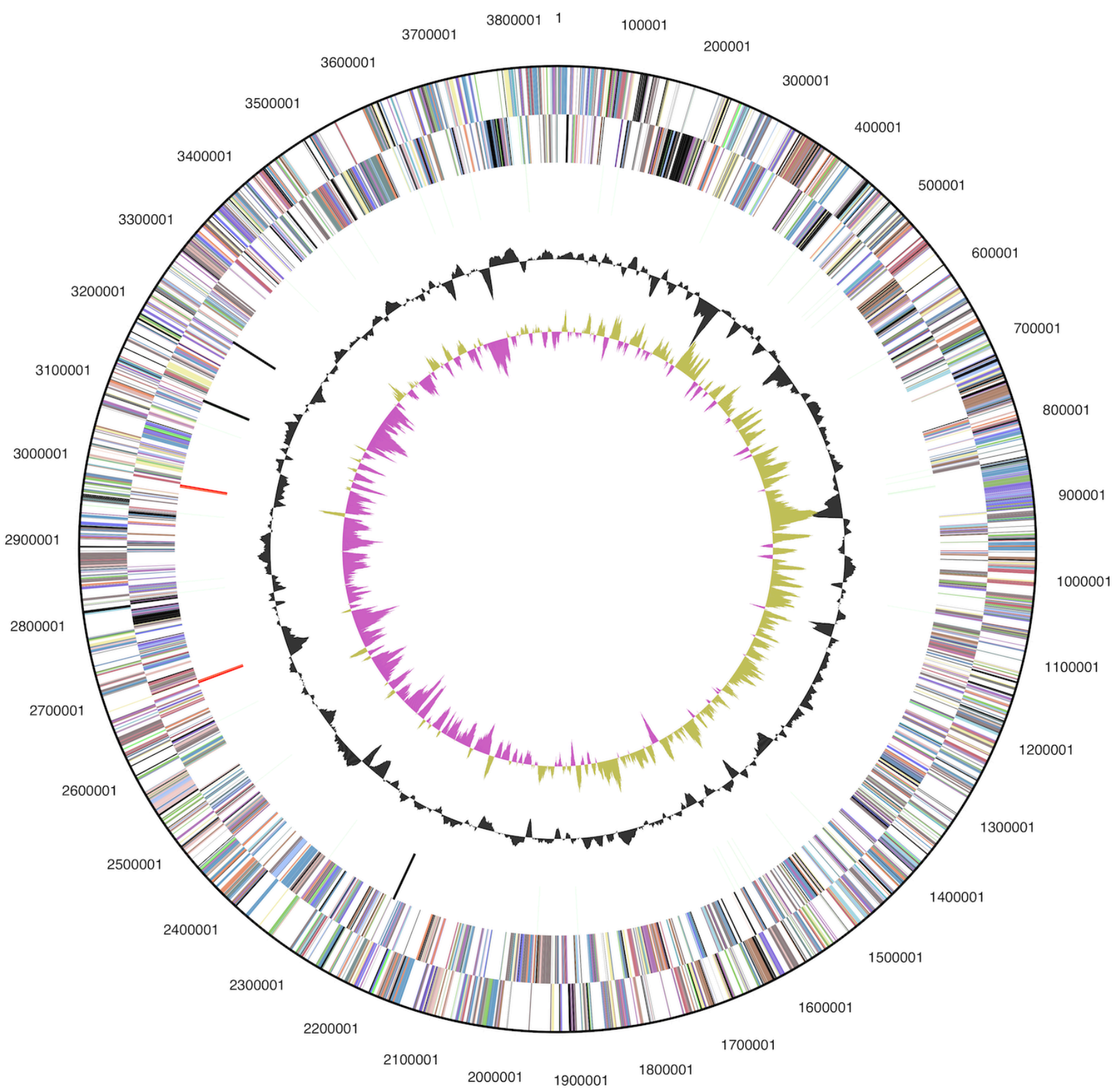

Figure 3. Graphical circular map of the chromosome. From outside to the center: Genes on forward strand (color by COG categories), Genes on reverse strand (color by COG categories), RNA genes (tRNAs green, rRNAs red, other RNAs black), GC content, GC skew. 
Table 3. Genome Statistics

\begin{tabular}{lrr}
\hline Attribute & Value & \% of Total \\
\hline Genome size (bp) & $3,851,869$ & $100.00 \%$ \\
DNA coding region (bp) & $3,410,010$ & $88.53 \%$ \\
DNA G+C content (bp) & $2,269,813$ & $58.93 \%$ \\
Number of replicons & 1 & \\
Extrachromosomal elements & 0 & \\
Total genes & 3,408 & $100.00 \%$ \\
RNA genes & 57 & $1.67 \%$ \\
rRNA operons & 2 & \\
Protein-coding genes & 3,351 & $98.33 \%$ \\
Pseudo genes & 68 & $2.00 \%$ \\
Genes with function prediction & 2,402 & $70.48 \%$ \\
Genes in paralog clusters & 492 & $14.44 \%$ \\
Genes assigned to COGs & 2,502 & $73.42 \%$ \\
Genes assigned Pfam domains & 2,623 & $76.97 \%$ \\
Genes with signal peptides & 1,073 & $31.48 \%$ \\
Genes with transmembrane helices & 812 & $23.83 \%$ \\
CRISPR repeats & 1 & \\
\hline
\end{tabular}

Table 4. Number of genes associated with the general COG functional categories

\begin{tabular}{crrl}
\hline Code & value & \%age & Description \\
\hline J & 155 & 5.6 & Translation, ribosomal structure and biogenesis \\
A & 1 & 0.1 & RNA processing and modification \\
K & 128 & 4.6 & Transcription \\
L & 154 & 5.6 & Replication, recombination and repair \\
B & 5 & 0.2 & Chromatin structure and dynamics \\
D & 28 & 1.0 & Cell cycle control, cell division, chromosome partitioning \\
Y & 0 & 0.0 & Nuclear structure \\
V & 45 & 1.6 & Defense mechanisms \\
T & 297 & 10.8 & Signal transduction mechanisms \\
M & 184 & 6.7 & Cell wall/membrane/envelope biogenesis \\
N & 106 & 3.8 & Cell motility \\
Z & 0 & 0.0 & Cytoskeleton \\
W & 0 & 0.0 & Extracellular structures \\
U & 83 & 3.0 & Intracellular trafficking and secretion, and vesicular transport \\
O & 106 & 3.8 & Posttranslational modification, protein turnover, chaperones \\
C & 274 & 9.9 & Energy production and conversion \\
G & 96 & 3.5 & Carbohydrate transport and metabolism \\
E & 185 & 6.7 & Amino acid transport and metabolism \\
F & 66 & 2.4 & Nucleotide transport and metabolism \\
H & 145 & 5.3 & Coenzyme transport and metabolism \\
I & 74 & 2.7 & Lipid transport and metabolism \\
P & 123 & 4.5 & Inorganic ion transport and metabolism \\
Q & 40 & 1.5 & Secondary metabolites biosynthesis, transport and catabolism \\
R & 274 & 9.9 & General function prediction only \\
S & 195 & 7.1 & Function unknown \\
- & 906 & 26.6 & Not in COGs \\
\hline & & &
\end{tabular}




\section{Acknowledgements}

We would like to gratefully acknowledge the help of Katja Steenblock (DSMZ) for growing D. propionicus cultures. This work was performed under the auspices of the US Department of Energy Office of Science, Biological and Environmental Research Program, and by the University of California, Lawrence Berkeley National Laboratory under contract No. DE-AC02-05CH11231,

\section{References}

1. Validation List no. 7. Validation of the publication of new names and new combinations previously effectively published outside the IJSB. Int I Syst Bacteriol 1981; 31:382-383. doi:10.1099/00207713-31-3-382

2. Widdel F. 1980. Anaerober Abbau von Fettsäuren und Benzoesäure durch neu isolierte Arten Sulfatreduzierender Bakterien. Dissertation. Georg August-Universität zu Göttingen.

Lindhorst/Schaumburg-Lippe, Göttingen, Germany, $443 \mathrm{p}$.

3. Garrity G. NamesforLife. BrowserTool takes expertise out of the database and puts it right in the browser. Microbiol Today 2010; 37:9.

4. Widdel F, Pfennig N. Studies on dissimilatory sulfate-reducing bacteria that decompose fatty acids II. Incomplete oxidation of propionate by Desulfobulbus propionicus gen. nov., sp. nov. Arch Microbiol 1982; 131:360-365.

doi:10.1007/BF00411187

5. Laanbroek HJ, Pfennig N. Oxidation of shortchain fatty acids by sulfate-reducing bacteria in freshwater and in marine sediments. Arch Microbiol 1981; 128:330-335. PubMed doi:10.1007/BF00422540

6. Kaksonen AH, Plumb JJ, Robertson WJ, Franzmann PD, Gibson JAE, Puhakka JA. Culturable diversity and community fatty acid profiling of sulfate-reducing fluidized-bed reactors treating acidic, metal-containing wastewater. Geomicrobiol J 2004; 21:469-480. doi:10.1080/01490450490505455

7. Lovley DR, Phillips EJP. Novel processes for anaerobic sulfate production from elemental sulfur by sulfate-reducing bacteria. Appl Environ Microbiol 1994; 60:2394-2399. PubMed

8. Tasaki M, Kamagata Y, Nakamura K, Okamura K, Minami K. Acetogenesis from pyruvate by Desulfotomaculum thermobenzoicum and differences in pyruvate metabolism among three sulfatereducing bacteria in the absence of sulfate. FEMS
Lawrence Livermore National Laboratory under Contract No. DE-AC52-07NA27344, and Los Alamos National Laboratory under contract No. DE-AC0206NA25396, UT-Battelle and Oak Ridge National Laboratory under contract DE-AC05-000R22725, as well as German Research Foundation (DFG) INST 599/1-2.

Microbiol Lett 1993; 106:259-263.

doi:10.1111/j.1574-6968.1993.tb05973.x

9. DeSantis TZ, Hugenholtz P, Larsen N, Rojas M, Brodie E, Keller K, Huber T, Dalevi D, Hu P, Andersen G. Greengenes, a chimera-checked $16 \mathrm{~S}$ rRNA gene database and workbench compatible with ARB. Appl Environ Microbiol 2006;

72:5069-5072. PubMed doi:10.1128/AEM.03006-05

10. Porter MF. An algorithm for suffix stripping. Program: electronic library and information systems 1980; 14:130-137. doi:10.1108/eb046814

11. Castresana J. Selection of conserved blocks from multiple alignments for their use in phylogenetic analysis. Mol Biol Evol 2000; 17:540-552. PubMed

12. Lee C, Grasso C, Sharlow MF. Multiple sequence alignment using partial order graphs. Bioinformatics 2002; 18:452-464. PubMed doi:10.1093/bioinformatics/18.3.452

13. Stamatakis $A$, Hoover $P$, Rougemont J. A rapid bootstrap algorithm for the RAxML Web servers. Syst Biol 2008; 57:758-771. PubMed doi:10.1080/10635150802429642

14. Pattengale ND, Alipour M, Bininda-Emonds ORP, Moret BME, Stamatakis A. How many bootstrap replicates are necessary? Lect Notes Comput Sci 2009; 5541:184-200. doi:10.1007/978-3-64202008-7_13

15. Liolios K, Chen IM, Mavromatis K, Tavernarakis $\mathrm{N}$, Hugenholtz P, Markowitz VM, Kyrpides NC. The Genomes On Line Database (GOLD) in 2009: status of genomic and metagenomic projects and their associated metadata. Nucleic Acids Res 2010; 38:D346-D354. PubMed doi:10.1093/nar/gkp848

16. Rabus R, Ruepp A, Frickey T, Rattei T, Fartmann B, Stark M, Bauser M, Zibat A, Lombardot T, Becker I, et al. The genome of Desulfotalea psychrophila, a sulfate-reducing bacterium from permanently cold Arctic sediments. Environ Micro- 
biol 2004; 6:887-902. PubMed

doi:10.1111/j.1462-2920.2004.00665.x

17. Field D, Garrity G, Gray T, Morrison N, Selengut J, Sterk P, Tatusova T, Thomson N, Allen MJ, Angiuoli SV, et al. The minimum information about a genome sequence (MIGS) specification. Nat Biotechnol 2008; 26:541-547. PubMed doi:10.1038/nbt1360

18. Woese CR, Kandler O, Wheelis ML. Towards a natural system of organisms: proposal for the domains Archaea, Bacteria, and Eucarya. Proc Natl Acad Sci USA 1990; 87:4576-4579. PubMed doi:10.1073/pnas.87.12.4576

19. Garrity GM, Holt JG. The Road Map to the Manual. In: Garrity GM, Boone DR, Castenholz RW (eds), Bergey's Manual of Systematic Bacteriology, Second Edition, Volume 1. Springer, New York 2001:119-169.

20. Validation List No. 107. List of new names and new combinations previously effectively, but not validly, published. Int I Syst Evol Microbiol 2006; 56:1-6. PubMed doi:10.1099/ijs.0.64188-0

21. Kuever J, Rainey FA, Widdel F. Class IV. Deltaproteobacteria class. nov. In: Garrity GM, Brenner DJ, Krieg NR, Staley JT (eds), Bergey's Manual of Systematic Bacteriology, Second Edition, Volume 2, Part C, Springer, New York, 2005, p. 922.

22. Kuever J, Rainey FA, Widdel F. Order III. Desulfobacterales ord. nov. In: Garrity GM, Brenner DJ, Krieg NR, Staley JT (eds), Bergey's Manual of Systematic Bacteriology, Second Edition, Volume 2, Part C, Springer, New York, 2005, p. 959.

23. Kuever J, Rainey FA, Widdel F. Family II. Desulfobulbaceae fam. nov. In: Garrity GM, Brenner DJ, Krieg NR, Staley JT (eds), Bergey's Manual of Systematic Bacteriology, Second Edition, Volume 2, Part C, Springer, New York, 2005, p. 988.

24. Laanbroek HJ, Abee T, Voogd IL. Alcohol conversions by Desulfobulbus propionicus Lindhorst in the presence and absence of sulfate and hydrogen. Arch Microbiol 1982; 133:178-184. doi:10.1007/BF00414998

25. Classification of bacteria and archaea in risk groups. http://www.baua.de TRBA 466.

26. Ashburner M, Ball CA, Blake JA, Botstein D, Butler $\mathrm{H}$, Cherry JM, Davis AP, Dolinski K, Dwight SS, Eppig JT, et al. Gene Ontology: tool for the unification of biology. Nat Genet 2000; 25:25-29. PubMed doi:10.1038/75556

27. Dannenberg S, Kroder M, Dilling W, Cypionka H. Oxidation of $\mathrm{H}_{2}$, organic compounds and inor- ganic sulfur compounds coupled to reduction of $\mathrm{O}_{2}$ or nitrate by sulfate-reducing bacteria. Arch Microbiol 1992; 158:93-99. doi:10.1007/BF00245211

28. Cypionka H, Widdel F, Pfennig N. Survival of sulfate-reducing bacteria after oxygen stress, and growth in sulfate-free oxygen-sulfide gradients. FEMS Microbiol Ecol 1985; 31:39-45. doi:10.1111/j.1574-6968.1985.tb01129.x

29. Laanbroek HJ, Geerligs HJ, Sijtsma L, Veldkamp $\mathrm{H}$. Competition for sulfate and ethanol among Desulfobacter, Desulfobulbus, and Desulfovibrio species isolated from intertidal sediments. Appl Environ Microbiol 1984; 47:329-334. PubMed

30. Fuseler K, Cypionka H. Elemental sulfur as an intermediate of sulfide oxidation with oxygen by Desulfobulbus propionicus. Arch Microbiol 1995; 164:104-109. doi:10.1007/BF02525315

31. Tasaki M, Kamagata Y, Nakamura K, Okamura K, Minami K. Acetogenesis from pyruvate by Desulfotomaculum thermobenzoicum and differences in pyruvate metabolism among three sulfatereducing bacteria in the absence of sulfate. FEMS Microbiol Lett 1993; 106:259-263. doi:10.1111/j.1574-6968.1993.tb05973.x

32. Stams AJM, Kremer DR, Nicolay K, Weenk GH, Hansen TA. Pathway of propionate formation in Desulfobulbus propionicus. FEMS Microbiol Lett 1988; 49:273-277.

33. Tasaki M, Kamagata Y, Nakamura K, Mikami E. Propionate formation from alcohols or aldehydes by Desulfobulbus propionicus in the absence of sulfate. J Ferment Bioeng 1992; 73:329-331. doi:10.1016/0922-338X(92)90195-Z

34. Kremer DR, Hansen TA. Pathway of propionate degradation in Desulfobulbus propionicus. FEMS Microbiol Lett 1988; 49:273-277. doi:10.1111/j.1574-6968.1988.tb02729.x

35. Taylor J, Parkes RJ. The cellular fatty acids of the sulphate-reducing bacteria, Desulfobacter sp., Desulfobulbus sp. and Desulfovibvio desulfuvicans. J Gen Microbiol 1983; 129:3303-3309.

36. Parkes RJ, Calder AG. The cellular fatty acids of three strains of Desulfobulbus, a propionateutilising sulphate-reducing bacterium. FEMS Microbiol Ecol 1985; 31:361-363. doi:10.1111/j.1574-6968.1985.tb01172.x

37. Klenk HP, Göker M. En route to a genome-based classification of Archaea and Bacteria? Syst Appl Microbiol 2010; 33:175-182. PubMed doi:10.1016/j.syapm.2010.03.003 
38. Wu D, Hugenholtz P, Mavromatis K, Pukall R, Dalin E, Ivanova NN, Kunin V, Goodwin L, Wu $M$, Tindall BJ, et al. A phylogeny-driven genomic encyclopaedia of Bacteria and Archaea. Nature 2009; 462:1056-1060. PubMed doi:10.1038/nature08656

39. List of growth media used at DSMZ: http://www.dsmz.de/microorganisms/media_list.p hp.

40. Gemeinholzer B, Dröge G, Zetzsche H, Haszprunar G, Klenk HP, Güntsch A, Berendsohn WG, Wägele JW. The DNA Bank Network: the start from a German initiative. Biopreservation and Biobanking (In press).

41. DNA Bank Network. http://www.dnabanknetwork.org

42. DOE Joint Genome Institute. http://www.jgi.doe.gov

43. Phrap and Phred for Windows. MacOS, Linux, and Unix. http://www.phrap.com

44. Zerbino DR, Birney E. Velvet: algorithms for de novo short read assembly using de Bruijn graphs. Genome Res 2008; 18:821-829. PubMed doi:10.1101/gr.074492.107
45. Han C, Chain P. 2006. Finishing repeat regions automatically with Dupfinisher. in Proceeding of the 2006 international conference on bioinformatics \& computational biology. Edited by Hamid R. Arabnia \& Homayoun Valafar, CSREA Press. June 26-29, 2006: 141-146.

46. Lapidus A, LaButti K, Foster B, Lowry S, Trong S, Goltsman E. POLISHER: An effective tool for using ultra short reads in microbial genome assembly and finishing. AGBT, Marco Island, FL, 2008.

47. Hyatt D, Chen GL, LoCascio PF, Land ML, Larimer FW, Hauser LJ. Prodigal: prokaryotic gene recognition and translation initiation site identification. BMC Bioinformatics 2010; 11:119. PubMed doi:10.1186/1471-2105-11-119

48. Pati A, Ivanova NN, Mikhailova N, Ovchinnikova G, Hooper SD, Lykidis A, Kyrpides NC. GenePRIMP: a gene prediction improvement pipeline for prokaryotic genomes. Nat Methods 2010; 7:455-457. PubMed doi:10.1038/nmeth.1457

49. Markowitz VM, Ivanova NN, Chen IMA, Chu K, Kyrpides NC. IMG ER: a system for microbial genome annotation expert review and curation. Bioinformatics 2009; 25:2271-2278. PubMed doi:10.1093/bioinformatics/btp393 